University of Wollongong

Research Online

Faculty of Social Sciences - Papers (Archive) Faculty of Arts, Social Sciences \& Humanities

$1-1-2016$

A personal constructivist approach for investigating the patterns of dependency of adolescents with autism spectrum disorder: case study of two families

Elizabeth Kate Cridland

University of Wollongong, liz_cridland@uow.edu.au

Peter Caputi

University of Wollongong, pcaputi@uow.edu.au

Beverly M. Walker

University of Wollongong, bwalker@uow.edu.au

Sandra C. Jones

Australian Catholic University, Sandra.Jones@acu.edu.au

Christopher A. Magee

University of Wollongong, cmagee@uow.edu.au

Follow this and additional works at: https://ro.uow.edu.au/sspapers

Part of the Education Commons, and the Social and Behavioral Sciences Commons

Research Online is the open access institutional repository for the University of Wollongong. For further information contact the UOW Library: research-pubs@uow.edu.au 


\title{
A personal constructivist approach for investigating the patterns of dependency of adolescents with autism spectrum disorder: case study of two families
}

\author{
Abstract \\ This research investigated the utility and practicality of dependency grids for capturing and presenting the \\ dependency distribution patterns of three adolescents with autism spectrum disorder. The investigation \\ also involved family members to explore their level of awareness of the adolescents' dependency \\ preferences. The grids were analyzed using a range of measures, including the uncertainty index and \\ partial order scalogram analysis. Findings indicate the adolescents had various ways of dispersing their \\ dependencies among their resources and differed in the types of support most used. Additionally, family \\ members differed in their awareness of the adolescents' preferences. The benefits and drawbacks of the \\ adolescents' dependency distribution patterns are discussed, as well as implications of these patterns for \\ family members. Ways in which dependency grids may be further used with this population in research \\ and clinical contexts are also considered.
}

\section{Keywords}

two, families, study, case, spectrum, autism, constructivist, adolescents, approach, dependency, patterns, investigating, disorder, personal

\section{Disciplines \\ Education | Social and Behavioral Sciences}

\section{Publication Details}

Cridland, E. K., Caputi, P., Walker, B. M., Jones, S. C. \& Magee, C. A. (2016). A personal constructivist approach for investigating the patterns of dependency of adolescents with autism spectrum disorder: case study of two families. Journal of Constructivist Psychology, 29 (1), 30-50. 


\begin{abstract}
This research investigated the utility and practicality of dependency grids for capturing and presenting the dependency distribution patterns of three adolescents with Autism Spectrum Disorder. The investigation also involved family members to explore their level of awareness of the adolescents' dependency preferences. The grids were analyzed using a range of measures including the Uncertainty Index and partial order scalogram analysis. Findings indicate the adolescents had various ways of dispersing their dependencies amongst their resources and differed in the types of support most utilized. Additionally, family members differed in their awareness of the adolescents' preferences. The benefits and drawbacks of the adolescents' dependency distribution patterns are discussed, as well as implications of these patterns for family members. Ways in which dependency grids may be further utilized with this population in research and clinical contexts are also considered.
\end{abstract}




\begin{abstract}
A personal constructivist approach for investigating the patterns of dependency of adolescents with autism spectrum disorder: Case study of two families
\end{abstract}

\title{
Introduction
}

Our dependence on others is evident across all stages of life, from infancy to senior years. Similarly, our dependencies cover all aspects of life, from the fundamental needs of food and shelter to the more complex desires of affection and friendship. Whilst the degree and nature of our dependencies may change over time, we remain integrally and complexly reliant on others throughout life.

The issue of interest when investigating an individual's dependency needs is their pattern of dependence on others. Based on a personal constructivist understanding, patterns of dependence may be understood to fall on a continuum ranging from undispersed to indiscriminate dependencies. Undispersed dependencies are characterized by restricted and inflexible constructions about available resources; whereby resources are rigidly perceived as either suitable or not suitable (Walker, 2005). Individuals with undispersed dependencies may attempt to have all of their needs met by a limited number of individuals (Walker, 2005). This style of dependence often leads to exhausting of resources; ineffectively utilizing the help of resources in areas to which they are not well suited; and/or being left vulnerable if their limited resources are no longer available (Beail \& Beail, 1958; Walker, 2005). If this occurs, individuals with undispersed dependencies may perceive no-one to be suitable in addressing their needs and become predominantly autonomous, despite the drawbacks of this approach (Walker, Ramsey, \& Bell, 1988). At the other end of the continuum, indiscriminate dependencies involve minimal differentiation amongst resources. Essentially, individuals with this style of dependency dispersion do not allocate their dependencies in a specified manner, leading to reliance on all resources for all challenges (Walker, 2005).

Optimal utilization of supports is considered to fall in the middle of the dispersion continuum and is characterized by effective dispersion of needs amongst a flexible and adaptive network of resources with a considered sense of which person is most suitable to help with a particular challenge (Beail, \& Beail, 1958; Chiari et al., 1994). This pattern of reliance on others is referred to as dispersed dependencies and, 
according to Kelly $(1955,1962)$, is developed by individuals over time as part of the maturation process. That is, children are recognized to be wholly dependent on parents/caregivers for all needs, but with the ongoing elaboration and revision of personal constructions that occurs over time, their dependencies become more differentiated so that ultimately they learn to "satisfy one need here and another there" (Kelly, 1955, p.914). This dispersion process is facilitated by the development of hierarchically structured constructs about others and dependencies (Bell, Winter, \& Bhandari, 2010). Such hierarchical organization of constructions allows us to interpret, understand, and anticipate situations more easily than if each situation was interpreted by its various, individual components (Kelly, 1955).

Dependency distribution is a largely social process; as the development of effectively dispersed dependencies relies on an awareness of others' perceptions and mindfulness to balance one's own needs with those of other people (Walker, 1990; 2005). For this reason, it is of interest to explore the dependency distribution patterns of individuals with Autism Spectrum Disorders (ASD), given the sociality deficits associated with this condition. That is, individuals with ASD evidence persistent and significant social communicative impairments, as well as restricted and repetitive behaviors and/or interests (American Psychiatric Association [APA], 2013). More specifically, individuals with ASD may exhibit significant social reciprocity difficulties, experience difficulty accommodating changes to routines, and have unique intolerances and/or sudden mood changes (Attwood, 2007; Jensen \& Spannagel, 2011). In addition to these core impairments, individuals with ASD often experience a range of sensory sensitivities, gastrointestinal issues, immune system irregularities, and sleep disturbances (Attwood, 2007; Solomon \& Chung, 2012). This combination of significant social impairment coupled with physical issues exacerbates the challenging nature of this condition (Gray, 2003; Jensen \& Spannagel, 2011; Seltzer et al., 2003).

Given the sociality deficits associated with ASD, it is unknown how effectively individuals with ASD disperse their dependency needs. Related to this, it is unclear how efficiently individuals with ASD communicate their dependency expectations, meaning family members may have difficulty understanding, and thus fulfilling, the dependency needs of individuals with ASD (Procter, 2000; 2001). 
Third, individuals with ASD have difficulty developing hierarchically structured construct systems due to their tendency to rely on networks of isolated constructs (Cridland, Caputi, Jones, \& Magee, 2013; Procter, 2001). Given the importance of hierarchically organized constructs for effective construing, it is unclear how effectively adolescents with ASD disperse their dependencies.

Of particular interest here are the dependency distribution patterns of adolescents with ASD, as adolescence is considered to be one of the most challenging developmental stages for individuals with ASD given the range of social, emotional, physical, and cognitive changes inherent within this period . Some key challenges for adolescents with ASD include adjusting to the increased academic, social, and cognitive demands of high school; exposure to, and participation in, a broader range of social roles; and learning how to manage sexual urges in socially appropriate ways (Cridlan et al., 2013; Hellemans, Colson, Verbraeken, Vermeiren, \& Deboutte, 2007; Seltzer et al., 2003; Shattuck et al., 2007).

Given the range of challenges integral to this period, identifying and receiving support from others is imperative for the adaptive coping of these adolescents (Pinkerton, \& Dolan, 2007). In doing so, an integrative support network is important, as different resources supply different types of support. For example, formal support services can provide practical support such as financial assistance and information whereas informal support predominantly provides emotional and social support (Bauminger, Shulman, \& Agam, 2003; Phelps, McCammon, Wuensch, \& Golden, 2009). Whilst support networks involve individuals at various levels of the community, the family provides the majority of support for adolescents with ASD (Bradford, 2010; Orsmond, \& Kuo, 2011;).

This studyexplored the dependency patterns of two adolescents with ASD and their family members' awareness of these dependencies. In doing so, the research used dependency grids, which are a personal constructivist tool used to explore the resources an individual utilizes when confronted by challenging situations (Beail, \& Beail, 1958; Bell, 2001; Walker, 2005). Further, dependency grids investigate the extent to which the needs of an individual are dispersed amongst others; which situations provoke help seeking by an individual; and which situations an individual may feel they have insufficient resources to utilize (Walker, 2005; Walker et al., 1988). The present study focused particularly on the 
adolescents' distribution of needs amongst family members, given the significant role the family plays in supporting adolescents with ASD (Bradford, 2010; Field, \& Hoffman, 1999). In addition to exploring who the adolescents relied on, the study investigated the types of support preferred by the adolescents, including emotion-focused, problem-focused, advocacy, education, and social support.

It was anticipated that the structured nature of the dependency grid would suit the processing style of individuals with ASD, given the proven efficacy of repertory grids with similar populations (Hare, 1997; Hare, Jones, \& Paine, 1999; Hare, Searson, \& Knowles, 2011; Mason, 2008; Thomas, Butler, Hare, $\&$ Green, 2011). To our knowledge, no research data are available about the use of dependency grids with adolescents with ASD. Therefore, a secondary aim of this research was to explore the efficacy of conducting dependency grids with adolescents with ASD.

The study also explored family awareness of the adolescents' dependency distributions using a modified version of the Family Grid (Procter, 1985). Family Grids involve family members completing grids for how they predict other family members would respond. In doing so, they provide a measure of communality (or similarity) between individual grids, which allows us to highlight areas of awareness versus misunderstanding in families (Procter, 1985). Repertory grids have been used with families living with ASD previously (Procter, 2000); however, to our knowledge dependency grids have not been used with this population. Therefore, this study aimed to explore the utility of conducting Family Dependency Grids with families living with ASD, as a means of assessing their awareness of the individual with ASD's distribution of dependency.

\section{Method}

\section{Sample}

The sample consisted of two families with an adolescent member with ASD. Eligibility criteria for the adolescents with ASD included having a formal diagnosis of $\mathrm{ASD}^{1}$, being male ${ }^{2}$, and attending mainstream

\footnotetext{
${ }^{1}$ All participants with ASD had received a formal diagnosis of Asperger's Syndrome from either a pediatrician or psychologist based on ASD criteria in the Diagnostic and Statistical Manual of Mental Disorders (DSM), fourth edition (APA, 2000). Given the classification changes in the DSM-V (APA, 2013), these diagnoses are referred to here as ASD.
} 
secondary schooling. Eligibility criteria for the families included having two adolescent children (one adolescent with ASD and one neurotypically developing [NTD] adolescent ${ }^{3}$ ); two parents who identify as the primary caregivers; all family members living at home a minimum of 5 days per week; the adolescent being the only family member formally diagnosed with ASD; and all family members having knowledge of the ASD diagnosis.

\section{Procedure}

Ethical approval was granted by the University's Human Research Ethics Committee prior to commencing participant involvement. The sample of convenience was recruited from participants involved in a previous research study who indicated their interest in being involved in future university research. The broad research aims were explained to participants by provision of an information sheet and an introductory meeting with the first author. Following ethical standards for research with children, written consent was obtained from the participants and their parents.

The dependency grid interviews were conducted based on recommendations outlined in Cridland et al (2014b), including conducting interviews with individual participants in a private space within the family home (e.g., study or quiet living area); conducting interviews at a preferred time for participants; and conducting interviews at an appropriate pace to facilitate accurate interpretation of interview questions. Interviews lasted for an average of approximately 30 minutes (range 20-70 minutes).

\section{Dependency Grids.}

Adolescents each completed two dependency grids; Grid 1 focused on the people they turn to in challenging situations and Grid 2 focused on the types of support utilized. To ensure consistency between

\footnotetext{
${ }^{2}$ The rationale for focusing on adolescent males with ASD was based on the current predominance of males diagnosed with ASD (Krahn, \& Fenton, 2012) and previous recommendations to acknowledge the influence of gender on research findings (Cridland, Jones, Caputi, \& Magee, 2014a; Hsiao, Tseng, Huang, \& Gau, 2013).

${ }^{3}$ From hereon, the adolescent participants with ASD will be referred to as 'adolescents' and the NTD adolescent siblings as 'siblings'/‘brother'/‘sister'.
} 
grids, the situations and resources were supplied ${ }^{4}$ (Green, 2004; Winter, 1994). Specifically, supplied situations included both general (e.g., 'Feeling sad') and ASD specific (e.g., 'Have questions about ASD') issues. The supplied situations remained consistent across Grids 1 and 2. Participants were also encouraged to add relevant situations and/or resources, which were included in analysis.

A dichotomous scale for allocating resources to situations was employed, following Kelly's original methodology (Button, 1985). However, based on recommendations for conducting grids with young people with disabilities ${ }^{5}$ (Ravenette, 1980, 2005; Thomas et al., 2011), an amended procedure for allocating resources was used. That is, adolescents sorted 'resource cards' according to which resource they would/would not use for each challenging situation, with the first author completing the grid accordingly. Instructions were framed in the present tense to ensure a focus on the adolescent's current dependency distribution (Talbot, Cooper, \& Ellis, 1991). The specific instruction for allocating cards in Grid 1 was, 'If this challenging situation happened right now, and these people were available, who would you turn to for help?' and 'If this challenging situation happened right now, what type of support would you use?' for Grid 2. These instructions were presented verbally and visually on a 'resource-card sorting mat'.

Family members completed a modified version of the Family Grid (Procter, 1985). More specifically, family members completed Grids 1 and 2 regarding how they perceived the adolescent would complete the grid. The specific instruction for Grid 1 was, 'If this challenging situation happened to your family member right now, and these people were available, who do you think he would turn to for help?' and for Grid 2 was, 'If this challenging situation happened right now, what type of support would your family member use?'. Family members completed the grids by either using the resource cards or directly completing the grids. As the focus was on the adolescents' dependency patterns, family members did not complete grids for their own dependencies.

\footnotetext{
${ }^{4}$ The supplied situations and resources were derived from interviews conducted with 37 participants (adolescents with ASD, mothers, fathers, and adolescent siblings) from 13 families, discussing common challenges and coping strategies for adolescents with ASD.

${ }^{5}$ In some contexts, ASD is considered a disability, more commonly however it is considered a condition (Attwood, 2007; Seligman, \& Darling, 2007).
} 


\section{Analysis}

Several summary measures proposed by Bell (2009) were calculated for each grid using the computer program Gridstat. The Uncertainty Index was calculated as the primary summary measure of each grid. This index provides a score (from 0-1) of the uncertainty associated with the allocation of dependencies to each resource. A score of 0 is provided when only one resource is utilized in a situation, representing no uncertainty in dependency allocation; and a score of 1 is provided when all resources are used for a situation. The Uncertainty Index was chosen over the traditional Dispersion of Dependency Index (Walker et al., 1988) due to the limitations of this index outlined in Bell (2001).

Following this, partial order scalogram analysis (POSAC) (Guttman, 1944) was conducted to model each grid. Specifically, POSAC orders the resource-situation to reflect the hierarchical relationships among resources and then uses an iterative algorithm to find a best-fitting configuration (Bell, 2001). The vertical dimension reflects the number of situations a resource is available for, with those towards the top being depended on in more situations. The POSAC analysis adds 'ideal' and 'minimum' resources at each extreme of the vertical dimension. The horizontal dimension reflects the differentiation of sets of situations covered by resources.

The other summary measures calculated included the 'Dependence Total', which reflects the overall number and percentage of resources utilized across all situations- with higher percentages reflecting greater dispersion. The 'Cognitive complexity' reflects the differentiation among resources and situations. The breadth of the POSAC hierarchy, referred to hereafter as the Breadth index, provides an indication of the degree of differentiation of sets of situations covered by the resources. The depth of the POSAC hierarchy, referred to hereafter as the Depth index, provides an indication of the variation in resource availability or complexity of the resource structure. The three most utilized resources and their corresponding percentages are also reported. 


\section{Results and discussion}

Summary measures for Grids 1 and 2 are presented in Table 1. For all measures, higher scores indicate greater dispersion of dependency.

\section{(Insert Table 1)}

Overall, the Uncertainty Indices indicate the adolescents report similar dispersions of dependencies amongst resources (Grid 1) and types of support sought (Grid 2). Additionally, based on cognitive complexity measures, each grid depicts similar degrees of differentiation among resources. The grids differ, however, in the way the resources were allocated. For example, in Grid 1 the distribution pattern for Adolescent 1 features less breadth than depth, indicating little differentiation of resources amongst situations but various resources available for certain circumstances. This is in contrast to Adolescent 2, whose distribution pattern features similar distribution between breadth and depth of dependency dispersion. Overall, the most utilized resources were problem-focused strategies such as 'Explain it to me', 'Sort out the problem', and 'Give me advice', with emotion-focused strategies such as 'Hug me' being the least utilized. The grids of each family are considered in detail below.

Family1. The members of Family 1 included a 16 year old male with Asperger's Syndrome and Tourette Syndrome (Adolescent 1), a 17 year old NTD female, a 19 year old NTD male (who no longer lives in the family home), and the mother and father (aged 44 and 47 years respectively). Participating members included the adolescent siblings residing in the home and the parents. However, all family members were included in the grids. Adolescent 1 attends a local secondary school, which he dislikes due to bullying and having to attend "boring subjects". Adolescent 1 described himself as "happyish" and "funny" and a person who enjoys spending time playing computer games with his older siblings. 
When completing the grids, Adolescent 1 adjusted the supplied resources by removing the 'other family' and 'someone outside family' resource-cards, saying these were not relevant to him. During the grid interview he was observed to have some difficulty generalizing about the resources he utilizes across situations and was reminded several times that there were no right or wrong answers. Upon completion of the activity, Adolescent 1 commented that he was "exhausted" but happy that he had been able to answer the questions.

Figure 1 presents Adolescent 1's grid data and Figure 2 shows the POSAC representation of Adolescent 1's grids.

(Insert Figure 1)

(Insert Figure 2)

Two independent dependency hierarchies were evident in Adolescent 1's dependency network. One hierarchy identified that Adolescent 1 relies on his siblings and mother for similar situations, with his older sister being the most utilized resource. In contrast, 'Myself', although substantially available, was an isolated resource. Inspection of the resources indicated the hierarchy for self-reliance was dominated by managing emotions (e.g., anger, sadness, loneliness), whilst the other hierarchy was used for practical and/or social issues, such as difficulties with homework, problems with friends, or questions about puberty. Adolescent 1's father was the least relied upon resource; but was specialized in that he was the sole person utilized for questions about puberty.

Adolescent 1's most sought after resources were problem-focused strategies (i.e., 'Give me advice', 'Explain it me to me', 'Help me sort out problem') over emotional (e.g., 'Give me a hug') or social (e.g., 'Play with me') strategies. The hierarchy focusing on problem solving strategies suggests a highly organized construct around the types of support utilized in specific situations. It is likely that this hierarchy corresponds with the dominant hierarchy in Grid 1 (see Figure 2). 
It is possible that the other hierarchy evident in Grid 2 (see Figure 2) corresponds with the 'reliance on self' hierarchy evident in Grid 1. This may mean, Adolescent 1 attempts to manage his emotions himself by distraction techniques such as playing games. However, as evident in the POSAC representation, there are no back-up strategies if this type of support is not effective.

Participant 1's family had reasonable awareness of his dependency patterns, as evidenced by the various summary measures. However, several points of incongruence were also identified. For example, all family members overestimated the cognitive complexity of Grid 1 compared to the adolescent's responses. Additionally, the adolescent's mother and sister considered him to lack depth of dispersion when distributing his dependency needs. For the mother this finding may indicate a different perspective about the amount that her son relied on her, and for the sister this finding suggests she perceives her brother utilized the same types of support across the majority of situations.

Half of Participant 1's dependencies were distributed amongst his two older siblings (see Table 1). However, none of the family members recognized the extent of his reliance on siblings. These differing perceptions may mean Participant 1 has difficulty communicating his preference for support from his siblings, the siblings do not meet all of Participant 1's needs, and/or family members do not recognize the amount of support the siblings provide Participant 1.

Regarding the types of support preferred by Participant 1, the mother and father overestimated the degree to which Participant 1 seeks to be left alone, while this strategy was one of his least preferred types of support. These results may mean Participant 1 has difficulty communicating his desire for support from other family members or alternatively family members may have greater awareness of the adolescents' utilization of 'alone-time' in challenging situations.

Family 2. The members of Family 2 include a 15 year old male with Asperger's Syndrome (Adolescent 2), an 18 year old NTD brother, and the mother and father (aged 51 and 50 years respectively). Observation during the interview and previous independent testing indicated Adolescent 2 is of high intelligence. Adolescent 2 attends a local secondary school and his favorite subjects are science and math. 
Adolescent 2 described himself as "energetic" and "quiet" and a person who enjoys spending time with friends.

When completing the grids, Adolescent 2 adjusted the supplied resources by removing the 'other family' and adding 'Tutor', 'Youth group leader', and 'Professional' (which was a combined resource representing his doctor, counselor and psychiatrist). During the grid interview, Adolescent 2 said he was "trying to use logic" to answer some of the questions, for example he thought it would be "illogical" to put 'Leave me alone' with any of the resources that involved obtaining the help of another person. The complex, and sometimes illogical, nature of help seeking was explained to Adolescent 2 several times throughout the interview. Upon completion of the activity, Adolescent 2 was concerned whether he had gotten the "answers correct".

Figure 3 presents the grid data for Adolescent 2 and Figure 4 shows the POSAC representation of Adolescent 2's grids.

(Insert Figure 3)

(Insert Figure 4)

Adolescent 2's dependency grid depicts various dependency hierarchies, which may be considered to reflect a dispersed pattern of dependencies. Alternatively, the dependency pattern may reflect Adolescent 2's 'logical' approach to dependency allocation rather than his actual distributions. Regardless, the complex dispersion of dependencies depicted in Figures 3 and 4 correspond with the comparatively high measures of complexity presented in Table 1. Contributing to the complexity of this grid is the larger number of resources $(n=7)$ utilized across situations compared to Adolescent 1.

Analysis of the resources indicates Adolescent2 relies most on his mother, and to a slightly lesser extent, father. Adolescent 2 also relied heavily on himself and his older brother, but these resources were somewhat independent from each other. More specifically, his older brother was relied on uniquely for problems with bullies, whilst Adolescent 2 was reliant on himself when feeling bored. 
Other independent, yet less utilized, resources were Adolescent 2's youth group leader and professionals. Inspection of the resources indicated Adolescent 2 relied predominantly on the professional resource for questions about puberty and ASD, and relied on his youth group leader for social challenges (e.g., 'Having difficulties making friends', 'Having difficulties with friends', and 'Feeling lonely'). It is possible that Adolescent 2 also utilized his youth group leader for spiritual issues, but these were not captured adequately in the items.

The POSAC representation for Grid 2 (Figure 4) shows a very different dispersion pattern from that of Participant 1, despite comparable Uncertainty Indices. Specifically, Figure 4 shows a dependency network dominated by largely independent support types with few hierarchies. Thus, Adolescent 2 may see different types of support as unique to different situations but, unlike the preceding grids, has little backup for these support types if they are not effective. This pattern of dependence is considered less cognitively complex, which is echoed in the comparatively low Cognitive Complexity score (see Table 1).

Similar to the grids of Adolescent 1, there is minimal utilization of emotional and social support strategies. Of particular interest, Adolescent 2 elected 'Hug me' as a strategy sought after in some of the situations where 'Leave me alone' was elected. The conflicting nature of these types of support may be difficult for significant others to understand and therefore fulfil.

Adolescent 2's family had comparatively high awareness of his dependency patterns, as evidenced by congruency amongst the various summary measures. Moreover, the overall similarity between the grids indicates the family members have a comparatively good awareness of the adolescent's dependency needs across a range of situations. Additionally, it may mean Adolescent 2 has a good ability to communicate his needs to his family.

One point of interest from the grids is that the mother and brother did not recognize the extent to which Adolescent 2 relied on himself. This could mean the mother and brother underestimate Adolescent 2's ability to self-manage in challenging situations. Alternatively, it could mean Adolescent 2 overestimates his coping skills and is not aware of the extent to which he relies on others. 


\section{General Discussion}

To our knowledge, this study is the first to explore the use of dependency grids with adolescents with ASD and their families. By involving family members, the study not only investigated the dependency patterns of the adolescents with ASD, but also the level of awareness family members had of the adolescents' dependency preferences.

The dependency grid proved to be a practical and sensitive approach for capturing and presenting the adolescents' unique dependency distribution patterns. Further, similar to repertory grids, the structured nature of the dependency grid interview (and the grid itself) was well suited to the interaction style of individuals with ASD (Hare et al., 1999). Also, the relatively short administration time needed to obtain a significant amount of information about the adolescents' dependency patterns provides support for the use of dependency grids with this population in both research and clinical settings.

The findings indicated several noteworthy issues. First, both adolescents reported that they relied significantly on their adolescent siblings for support. More specifically, siblings were identified as being in the top three most utilized resources and/or were the preferred sources of support for particular situations for each adolescent. These findings are in line with the literature which indicates siblings provide both significant and unique supporting roles for their sibling with ASD (Benderix, \& Sivberg, 2007; Carrillo, 2012; Orsmond, \& Seltzer, 2009). It is important that the significant role siblings often provide for the family member with ASD is acknowledged, and that they themselves are provided with adequate support (Smith, \& Perry, 2005; Pilowsky, Yirmiya, Doppelt, Gross-Tsur, \& Shalev, 2004). Further, it is vital that parents monitor the caregiving responsibilities that siblings undertake to avoid siblings becoming overburdened. Research indicates these issues are of particular importance with adolescent siblings of individuals with ASD, given their heightened awareness of the care-giving demands placed on parents and the siblings' increased capability for undertaking greater responsibilities (Benderix, \& Sivberg, 2007; Morgan, 1988; Seligman, \& Darling, 2007).

Another pertinent finding was that emotion-focused strategies were the least sought after type of support identified by the adolescents, with both participants preferring problem-focused strategies. These 
findings suggest the adolescents perceived greater benefit from solution-focused support such as having someone explain an issue or help 'sort out' a situation rather than support which focused on the emotional aspects of a situation. This type of support is in line with the often practical nature of individuals with ASD. That is, research indicates that these individuals tend to focus on cognitive aspects of a problem over emotional aspects (Altiere, \& von Kluge, 2009; Bauminger, 2002; Krahn, \& Fenton, 2012). These findings are important for families, as they may focus on providing emotional support if they perceive their family member with ASD to be struggling with a challenging situation (Bradford, 2010). As an aside, the finding that adolescents with ASD did not identify emotional support as helpful as other strategies does not indicate they do not experience emotional reactions to challenging situations (Bauminger, Shulman, \& Agam, 2003; Cottenceau, Roux, Blanc, Lenoir, Bonnet-Brilhault, \& Barthelemy, 2012).

The Family Grids provided insight into the level of awareness family members had of the adolescents' dependency preferences. Overall, the Family Grids showed high levels of communality, which may be indicative of awareness of the adolescents' dependency preferences. Whilst high levels of awareness between grids have been interpreted as a sign of healthy communication between individuals (O'Laughlin, 1989; Ryle, \& Breen, 1972a), it may also be indicative of family awareness of obvious ineffective dependency distribution patterns. For example, several family members commented on the adolescent's preference for people to 'sort out' challenging situations over collaborative problem solving (which does not encourage active learning). Additionally, whilst the Family Grids showed overall high levels of communality, there were areas of misperception in each family. These findings reflect the real world nature of families, in which there are areas of miscommunication and limited understanding which could be improved on, in even the most positively functioning families (Bowen, 1995). It is also important to consider that the family grids were compared against the adolescents' responses, which are a subjective assessment of their dependency patterns rather than an objective assessment of their help seeking preferences.

\section{Limitations}

Despite the various benefits of using dependency grids with adolescents with ASD and their families, there are components of the study which should be considered when interpreting findings. First, the use of 
supplied elements and resources was employed for time efficiency and consistency across participants. The limitations of supplied resources and elements include the possibility of some elements/resources having minimal relevance for some participants and/or participants having varied interpretations of the same elements/resources (Fiske, 1995; Fransella, \& Bannister, 2004). This issue may be particularly relevant when considering individuals with ASD given their difficulty elaborating on meanings of words due to concrete thinking styles and the possibility of unique uses of words (Cridland et al., 2014b; Gold, \& Faust, 2012; Koning, \& Magill-Evans, 2001). Several steps were taken to address this issue. First, the interviewer explained each resource and element to the adolescents prior to the interview and also encouraged participants to clarify any issues they did not understand throughout the interview. Second, participants were encouraged to add elements and resources to increase the relevance of their grid. Additionally, task instructions were presented visually to participants to minimize potential misinterpretation from verbal instructions.

Despite these considerations, it is possible that there were variations in the way the adolescents interpreted the situations and resources, which should be noted when considering the findings. For example, Adolescent 2 had difficulty operating in the 'as if' mode, as his allocation of resources often focused on whether he had utilized the resources previously. He also made several comments about using 'logic' to work out the 'right' answer, which was likely to impact on his resource allocation. It is, therefore, important to interpret the findings within their scope; that is, as a case study investigation, which does not claim to be representative of all adolescents with ASD. In addition tothis, the participants were both relatively high functioning, meaning their ability to complete the dependency grids may not be reflective of other adolescents with ASD.

In addition, it is necessary to recognize that the whilst the grids provided a comprehensive representation of the adolescents' dependency patterns, in reality they only provide a snapshot of how these individual disperse their dependencies and how they construe the world more generally (Fransella et al., 2004). For efficiency, the findings were based on the mean POSAC representations, meaning only a general 
level of analysis was presented. This means it is possible the findings underestimate the complexity of the adolescents' dependency networks.

There are also some issues to consider regarding the Uncertainty Index (Bell, 2001), which was used as a measure of dependency dispersion. As Bell (2009) explains, the Uncertainty Index does not account for the relationship between situations and resources, as it is a univariate index. This means the Uncertainty Index treats all circumstances equally, despite that in some circumstances an integrated network of resources is considered healthy, whilst in other situations it may indicates an unhealthy pattern of overdependence (Bell, 2009).

\section{Recommendations}

This study provides preliminary support for the use of dependency grids with adolescents with ASD and their families in both research and clinical settings. However, further research is needed to clarify their efficacy. Based on the issues raised in this investigation, the following areas warrant further research:

1. Further studies investigating the use of dependency grids with individuals with ASD are needed. Such research may involve children with ASD and/or individuals with lower functioning ASD. Such studies may explore the use of alternative administration approaches, such as pictures or photographs. Additionally, this research may explore the utility of conducting dependency grids with other significant resources for adolescents with ASD such as teachers, health professionals, counselors, and friends.

2. Research is needed to investigate how adolescents with ASD construe the dependency patterns of family members. Such research may involve having family members complete their own dependency grids, with the adolescents completing subsequent grids predicting their family members' responses.

3. Future studies may benefit from eliciting individualized rather than prescribed resources and elements to ensure participants have personalized grids. Such research will also investigate adolescents' with ASD's ability to engage in the process of construct elicitation.

4. Future research may compare the dependency distribution patterns of individuals with ASD with those of NTD individuals to determine whether there are any differential trends amongst these groups. For 
example, the adolescents in the current investigation predominantly relied on problem-focused support; however it is unclear whether this is similar to the preferred support of NTD teens.

5. Future research would benefit from formally investigating adolescents with ASD and their families' experiences of completing dependency grids. Such investigations may help determine the utility of conducting dependency grids with this population and may facilitate the processes of administering the grids. 6. More work is needed to investigate methods of statistically analyzing grids which provide relevant and detailed information about the data. In doing so, likert scales or rating systems could be utilized rather than dichotomous coding to provide further information about dependency distribution patterns.

The study also provides further rationale for the use of the dependency grids in clinical practice with adolescents with ASD and their families. The following recommendations highlight ways dependency grids could potentially facilitate clinical assessment and/or therapy with this population:

1. Dependency grids could be used in the assessment stages of therapy with individuals with ASD and their families. Such assessment may help identify various components of family functioning such as the roles of different members within the family system and the level of awareness family members have of each other's dependency needs. Additionally, dependency grids may be used to monitor the progress of therapy for individuals with ASD who have undispersed or indiscriminate dependency patterns.

2. Dependency grids many be used to facilitate discussions about the types of support utilized by adolescents with ASD and the efficacy of these supports. From here, informal behavioral experiments testing the efficacy of different types of support could be conducted with the adolescent to facilitate optimal support seeking. For example, an adolescent may use distraction in the form of video games to manage frustration when completing homework assignments. A series of behavioral experiments with the adolescent may help them recognize that problem-solving strategies for managing homework assignments are more efficacious than distraction techniques. 
3. Dependency grids may be used to facilitate communication between individuals with ASD and their family in daily interactions. The application of this communication may involve amendments to the grid process, such as the card-sorting approach used in this study.

\section{Conclusion}

This investigation provided further support for the value of a personal construct approach in working with individuals with ASD and their families. Conducting dependency grids with the adolescents with ASD and their families proved to be an efficacious approach for assessing and presenting the dependency distributions of these individuals. Additionally, the approach was helpful for communicating the adolescents' dependency patterns to their family members, which may facilitate their general understanding of the adolescent and how to best support them. It is important we continue to investigate approaches to understand the experiences of adolescents with ASD and develop strategies to assist them communicating with others. 


\section{References}

Altiere, M.J., \& von Kluge, S. (2009). Searching for acceptance: Challenges encountered while raising a child with autism. Journal of Intellectual \& Developmental Disability, 34(2), 142-152.

American Psychiatric Association. (2013). Diagnostic and Statistical Manual of Mental Disorders (5th ed.). Arlington: American Psychiatric Publishing.

Attwood, T. (2007). The Complete Guide to Asperger's Syndrome. London: Jessica Kingsley Publishers.

Cridland, E.K., Caputi, P., Jones, S.C., \& Magee, C. A. (2013). Understanding high functioning autism during adolescence: A personal construct theory approach. The Journal of Intellectual and Developmental Disability 39(1), 108-118.

Cridland, E.K., Jones, S.C., Caputi, P., \& Magee, C.A. (2014a). Being a girl in a boys' world: Investigating the experiences of girls with autism spectrum disorders during adolescence. Journal of Autism and Developmental Disorders, 44, 1261-1274.

Cridland, E.K., Jones, S.C., Caputi, P., \& Magee, C.A. (2014b). Qualitative research with families living with autism spectrum disorders: Recommendations for conducting semi-structured interviews. Journal of Intellectual \& Developmental Disability Advanced Online Edition. doi:

$10.3109 / 13668250.2014 .964191$

Bauminger, N. (2002). The facilitation of social-emotional understanding and social interaction in highfunctioning children with autism: Intervention outcomes. Journal of Autism and Developmental Disorders, 32(4), 283-298.

Bauminger, N., Shulman, C., \& Agam, G. (2003). Peer interaction and loneliness in high-functioning children with autism. Journal of Autism and Developmental Disorders, 33(5), 489-507.

Beail, N., \& Beail, S. (1958). Evaluating Dependency. In N. Beail (ed.), Repertory Grid Technique and Personal Constructs: Applications in Clinical and Educational Settings. Cambridge: Brookline Books.

Bell, R.C. (2001). Some new measures of the dispersion of dependency in a situation-resource grid. Journal of Constructivist Psychology, 14(3), 227-234. 
Bell, R.C. (2009). Gridstat5: A Program for Analysing the Data of a Repertory Grid. Melbourne: Author.

Bell, R.C., Winter, D.A., \& Bhandari, S. (2010). Hierarchical relationships in dependency grids: Explorations in survivors of childhood sexual abuse. Journal of Constructivist Psychology, 23(2), 102-117.

Benderix, Y., \& Sivberg, B. (2007). Siblings' experiences of having a brother or sister with autism and mental retardation: A case study of 14 siblings from five families. Journal of Paediatric Nursing, 22(5), 410-418.

Beresford, B.A. (1994). Resources and strategies: How parents cope with the care of a disabled child. Journal of Child Psychology and Psychiatry, and Allied Disciplines, 35(1), 171-209.

Bowen, M. (1995). Clinical view of the family. Family Systems, 2(2), 153-156.

Bradford, K. (2010). Supporting families dealing with autism and asperger's disorders. Journal of Family Psychotherapy, 21(2), 149-156.

Brewin, B.J., Renwick, R., \& Fudge Schormans, A. (2008). Parental perspectives of the quality of life in school environments for children with asperger syndrome. Focus on Autism and Other Developmental Disabilities, 23(4), 242-252.

Button, E. (1985). Personal Construct Theory and Mental Health. London: Croom Helm.

Card, N.A., Stucky, B.D., Sawalani, G.M., \& Little, T.D. (2008). Direct and indirect aggression during childhood and adolescence: A meta-analytic review of gender differences, intercorrelations, and relations to maladjustment. Child Development, 79(5), 1185-1229.

Carrillo, V. (2012). Growing up with autism: The sibling experience. Unpublished doctoral dissertation, California State University, Long Beach.

Chiari, G., Nuzzo, M.L., Alfano, V., Brogna, P., D'Andrea, T., Di Battista, G., et al. (1994). Personal paths of dependency. Journal of Constructivist Psychology, 7(1), 17-34.

Cottenceau, H., Roux, S., Blanc, R., Lenoir, P., Bonnet-Brilhault, F., \& Barthelemy, C. (2012). Quality of life of adolescents with autism spectrum disorders: Comparison to adolescents with diabetes. European Journal of Child and Adolescent Psychiatry, 21, 289-296. 
Field, S., \& Hoffman, A. (1999). The importance of family involvement for promoting self-determination in adolescents with autism and other developmental disabilities. Focus on Autism and Other Developmental Disabilities, 14(1), 36-41.

Fiske, S.T. (1995). Words! Words! Words! Confronting the problem in observations. In P.E. Shrout \& S.T. Fiske (eds.), Personality Research, Methods and Theory (pp. 222-239). Hillsdale: Lawrence Erlaum Associates Publishers.

Fong, L., Wilgosh, L., \& Sobsey, D. (1993). The experience of parenting an adolescent with autism. International Journal of Disability, Development and Education, 40(2), 105-113.

Fransella, F., \& Bannister, D. (2004). A Manual for Repertory Grid Technique (Second ed.). Chichester: John Wiley and Sons, Ltd.

Gold, R., \& Faust, M. (2012). Metaphor comprehension in persons with asperger's syndrome: Systemized versus non-systemized semantic processing. Metaphor and Symbol, 27(1), 55-69.

Gray, D.E. (2002). Ten years on: A longitudinal study of families of children with autism. Journal of Intellectual \& Developmental Disability, 27(3), 215-222.

Green, B. (2004). Personal construct psychology and content analysis. Personal Construct Theory \& Practice, 1, 82-91.

Guttman, L. (1944). A basis for scaling qualitative data. American Sociological Review, 9, 139-150.

Hare, D.J. (1997). Use of repertory grid techniques in working with people with learning disabilities. Journal of Intellectual Disabilities, 1, 115-119.

Hare, D.J., Jones, J.P.R., \& Paine, C. (1999). Approaching reality: The use of personal construct assessment in working with people with asperger syndrome. Autism, 3(2), 165-176.

Hare, D.J., Searson, R., \& Knowles, R. (2011). Real listening- Using personal construct assessment with people with intellectual disabilities: Two case studies. British Journal of Learning Disabilities, 39(3), 190-197. 
Hellemans, H., Colson, K., Verbraeken, C., Vermeiren, R., \& Deboutte, D. (2007). Sexual behavior in highfunctioning male adolescents and young adults with autism spectrum disorder. Journal of Autism and Developmental Disorders, 37(2), 260-269.

Hsiao, M.N., Tseng, W.L., Huang, H.Y., \& Gau, S.S.F. (2013). Effects of autistic traits on social and school adjustment in children and adolescents: The moderating roles of age and gender. Research in Developmental Disabilities, 34(1), 254-265.

Humphrey, N. (2008). Autistic spectrum and inclusion: Including pupils with autistic spectrum disorders in mainstream schools. Support for Learning, 23(1), 41-47.

Kaminsky, L., \& Dewey, D. (2001). Siblings relationships of children with autism. Journal of Autism and Developmental Disorders, 31(4), 399-410.

Kelly, G. (1955). The Psychology of Personal Constructs (Vol. 1 and 2). New York: Routledge.

Kelly, G. (1962). In whom confide: On whome depend for what? In B. Maher (ed.), Clinical Psychology and Personality: The Selected Papers of George Kelly (pp. 189-206). New York: Robert E. Kreiger Publishing Company.

Krahn, T., \& Fenton, A. (2012). The extreme male brain theory of autism and the potential adverse effects for boys and girls with autism. Journal of Bioethical Inquiry, 9(1), 93-103.

Koning, C., \& Magill-Evans, J. (2001). Social and language skills in adolescent boys with asperger syndrome. Autism, 5(1), 23-36.

Levy, A., \& Perry, A. (2011). Outcomes in adolescents and adults with autism: A review of the literature. Research in Autism Spectrum Disorders, 5(4), 1271-1282.

Mason, J. (2008). Measuring psychological change in offenders with intellectual disabilities and alcohol misuse using repertory grids: Two case examples. The British Journal of Forensic Practice, 10(4), $37-44$.

McHale, S.M., Kim, J., \& Whitman, S.D. (2006). Sibling relationships in childhood and adolescence. In P. Noller \& J.A. Feeney (eds.), Close Relationships: Functions, Forms and Processes (p. 127-149). New York: Psychology Press. 
McGovern, C.W., \& Sigman, M. (2005). Continuity and change from early childhood to adolescence in autism. Journal of Child Psychology and Psychiatry, 46(4), 401-408.

Morgan, S.B. (1988). The autistic child and family functioning: A developmental-family systems perspective. Journal of Autism and Developmental Disorders, 18(2), 263-280.

Myers, S.M., \& Johnson, C.P. (2007). Management of children with autism spectrum disorders. American Academy of Pediatrics, 120(5), 1162-1182.

Orsmond, G.I., \& Kuo, H.Y. (2011). The daily lives of adolescents with an autism spectrum disorderDiscretionary time use and activity partners. Autism, 15(5), 579-599.

Orsmond, G.I., \& Seltzer, M.M. (2009). Adolescent siblings of individual with an autism spectrum disorder: Testing a diathesis-stress model of sibling well-being. Journal of Autism Developmental Disorders, 39, 1053-1065.

Phelps, K.W., McCammon, S.L., Wuensch, K.L., \& Golden, J.A. (2009). Enrichment, stress, and growth from parenting an individual with autism spectrum disorder. Journal of Intellectual and Developmental Disability, 34(2), 133-141.

Pilowsky, T., Yirmiya, N., Doppelt, O., Gross-Tsur, V., \& Shalev, R.S. (2004). Social and emotional adjustment of siblings of children with autism. Journal of Child Psychology and Psychiatry, 45(4), 855-865.

Pinkerton, J., \& Dolan, P. (2007). Family support, social capital, resilience and adolescent coping. Child \& Family Social Work, 12(3), 219-228.

Procter, H. (1985). Repertory grids in family therapy and research. In N. Beail (ed.), Repertory Grid Technique and Personal Constructs: Applications in Clinical and Educational Settings (p. 218-239). Cambridge: Brookline Books.

Procter, H. (2000). Autism and family therapy: A personal construct approach. In S.D. Powell (ed.), Helping Children with Autism to Learn (p. 63-77). London: David Fulton Publishers.

Procter, H. (2001). Personal construct psychology and autism. Journal of Constructivist Psychology, 14, 107126. 
Ravenette, A. (1980). The Exploration of consciousness: Personal construct intervention with children. In A.W. Landfield \& L.M. Leitner (eds.), Personal Construct Psychology: Psychotherapy and Personality. New York: John Wiley \& Sons.

Ravenette, T. (2005). Constructive intervention with children when presented as problems. In F. Fransella (ed.), The Essential Practitioner's Handbook of Personal Construct Psychology. Chichester: John Wiley \& Sons

Ryle, A., \& Breen, D. (1972a). A comparison of adjusted and maladjusted couples using the double dyad grid. British Journal of Medical Psychology, 45, 375-382.

Ryle, A., \& Breen, D. (1972b). The use of the double dyad grid in the clinical setting. British Journal of Medical Psychology, 45, 383-389.

Secord, P.F., \& Greenwood, J.D. (1995). Self-knowledge of psychological states: The status of subjects' accounts. In P.E. Shrout \& S.T. Fiske (eds.), Personality Research, Methods and Theory. Hillsdale: Lawrence Erlbaum Associates Publishers.

Seligman, M., \& Darling, R.B. (2007). Ordinary Families, Special Children: A Systems Approach to Childhood Disability. New York: Guilford Press.

Seltzer, M.M., Krauss, M.W., Shattuck, P.T., Orsmond, G., Swe, A., \& Lord, C. (2003). The symptoms of autism spectrum disorders in adolescence and adulthood. Journal of Autism and Developmental Disorders, 33(6), 565-581.

Smith, T., \& Perry, A. (2005). A sibling support group for brothers and sisters of children with autism. Journal of Developmental Disabilities, 11(1), 77-86.

Shattuck, P.T., Seltzer, M.M., Greenberg, J.S., Orsmond, G.I., Bolt, D., Kring, S., et al. (2007). Change in autism symptoms and maladaptive behaviours in adolescents and adults with an autism spectrum disorder. Journal of Autism and Developmental Disorders, 37, 1735-1747.

Solomon, A.H., \& Chung, B. (2012). Understanding autism: How family therapists can support parents of children with autism spectrum disorders. Family Process, 51(2), 250-264. 
Stoddart, K. (1999). Adolescents with asperger syndrome- Case studies of individual and family therapy. Autism, 3, 255-271.

Talbot, R., Cooper, C.L., \& Ellis, B. (1991). Uses of the dependency grid for investigating social support in stressful situations. Stress Medicine, 7(3), 171-180.

Thomas, S., Butler, R., Hare, D.J., \& Green, D. (2011). Using personal construct theory to explore self-image with adolescents with learning disabilities. British Journal of Learning Disabilities, 39, 225-232.

Walker, B.M. (1990). Construing George Kelly's construing of the person-in-relation. International Journal of Personal Construct Psychology, 3(1), 41-50.

Walker, B.M. (2005). Making sense of dependency. In F. Fransella (ed.), The Essential Practitioner's Handbook of Personal Construct Psychology (p. 78-86). Chichester: John Wiley and Sons.

Walker, B.M., Ramsey, F.L., \& Bell, R.C. (1988). Dispersed and undispersed dependency. International Journal of Personal Construct Psychology, 1(1), 63-80.

Winter, D.A. (1994). Personal Construct Psychology in Clinical Practice: Theory, Research and Applications. London: Routledge. 